\title{
The prevalence of shoulder and hand complications and associated factors among diabetic patients at University of Gondar Teaching Referral Hospital in Northwest Ethiopia
}

\author{
Solomon Fasika ${ }^{1 *}$, Solomon Mekonnen Abebe ${ }^{1}$ and Assefa Getachew Kebede ${ }^{2}$ \\ *Correspondence: sfsolaesta599@gmail.com \\ 'Department of Physiotherapy, University of Gondar, Ethiopia. \\ ${ }^{2}$ Department of Radiology, University of Gondar, Ethiopia.
}

\begin{abstract}
Background: Diabetes mellitus (DM) and associated long term complications have become increasingly prevalent in developing countries. However, there is little evidence on the extent of shoulder and hand musculoskeletal complications in Ethiopia.

Objective: This study aimed to assess the prevalence of shoulder and hand musculoskeletal complications and their associations among diabetic patients.

Method: An institution based cross-sectional study was conducted from March to June, 2012 at the University of Gondar Teaching Referral Hospital. The systematic sampling technique was used to select $301 \mathrm{DM}$ patients. To collect the data interviews and examination on hands and shoulders were conducted.

Results: Out of the total 301 subjects, $163(54.2 \%)$ were female. The mean age $( \pm S D)$ of the subjects was $45.9( \pm 15.9)$ years. The cumulative prevalence of shoulder and hand complications was $16.6 \%$ and the majority of them in females $36(20.1 \%)$. The prevalence was higher $37(21.3 \%)$ in type 2 DM patients. The bivariate logistic regression analysis showed that shoulder and hand complication was significantly associated with sex, type of diabetes, age and duration of DM illness; $(p<0.05)$. However, in multivariate logistic regression analysis, only sex had a significant association with shoulder and hand complications ( $\mathrm{p}=0.04)$.

Conclusion: The prevalence of shoulder and hand musculoskeletal complications was high in the Ethiopian DM population, and was higher in female and in older patients. Examination of the shoulder and the hand should then be included as an integral part of the care for diabetic patients.
\end{abstract}

Key words: Diabetes mellitus, musculoskeletal complication, frozen shoulder, carpal tunnel syndrome, dupuytren's contracture, trigger finger

\section{Introduction}

Diabetes mellitus (DM) is one of the most debilitating common chronic diseases across the globe known by increased blood glucose, resulting from defects in insulin secretion, insulin action, or both. Its burden continues to increase with the changing lifestyles of human beings, characterized by reduced physical activity, and increased obesity [1]. Based on the global estimate by the International Federation of Diabetes (IDF), DM prevalence in 2011 was 366 million people; and this is expected to rise to 552 million by 2030 [1]. The projected growth of DM in sub-Saharan Africa is high at $91 \%$, with those affected increasing from 14.7 million in 2011 to 28 million in 2030 [1]. According to the extrapolated data, the prevalence of DM in Ethiopia was 3.4\% in 2011 and estimated to rise to $3.7 \%$ by 2030 [1].

Several abnormalities of the shoulder and the hand have been described in diabetic patients. DM affects connective tissues in many ways and causes different alterations in periarticular and skeletal systems [2]. There is more prevalence of musculoskeletal (MSK) disorders of the shoulder and the hand in DM patients compared with the general population [3]. The increasing prevalence of DM and longer life expectancy of the diabetic patient have contributed to an increased frequency of clinically important alterations in the MSK system [5].

The exact pathophysiology of most of these MSK disorders remains obscure. However, connective tissue disorders, neuropathy, vasculopathy or combinations of these problems, may underlie the increased incidence of MSK disorders in DM [5]. The most commonly recognized and studied shoulder and hand MSK complications are frozen shoulder, limited joint mobility, trigger finger, Dupuytren's contracture, and carpal tunnel syndrome [4].

Frozen shoulder has been reported as a common complication in DM patients with a prevalence ranging from $11 \%$ to $30 \%[3,4,6,7,8,9,10]$, and its occurrence is associated with the duration of diabetes and age $[8,11]$. 
The prevalence of limited joint mobility of the hand in DM patient has been found to be quite variable, ranging from $8 \%$ to $50 \%[4,12]$, and its prevalence increased significantly with the duration of diabetes. Diabetic patients with a frozen shoulder are more likely to have limited joint mobility of the hand than DM patients without a frozen shoulder [4].

Dupuytren's contracture is a complication of the hand that has been reported in $16-42 \%$ of DM patients. Its prevalence increases with disease duration $[3,4,7]$. Carpal tunnel syndrome is seen in up to $20 \%$ of diabetic patients and its prevalence generally increases with duration of diabetes $[3,4,13]$. Trigger finger, also called stenosing flexor tenosynovitis, is another frequent diabetic complication with a prevalence ranging from $11-28 \%$ in diabetic patients associated with the duration of diabetes and age $[4,12,13,14]$.

Complications of DM are numerous and can affect different body systems. Involvement of the MSK system is common and can result in disability [4]. However, it is usually overlooked in clinical and research practices. Higher levels of complications result when the control of DM is poor. Poor glycaemic control can lead to worsening of certain MSK conditions [12]. Sex, age, duration of DM, type of DM, microvascular complications and poor glycaemic control were the identified factors associated with the presence of MSK complications in DM patients $[3,4,7,8,12,13,14]$.

Though various studies revealed a significantly higher rate of shoulder and hand complication in DM patients, there is limited evidence from East Africa, particularly in Ethiopia. To the author's knowledge, no study has been conducted to assess the prevalence and associated factors of MSK complications among DM patients in Ethiopia. Hence, this study will provide valuable information for decision makers, health care planners, evaluators and medical practitioners for promoting better health, quality of life, and the prevention of disability. Therefore, the objective of the study is to determine the prevalence and associated factors of shoulder and hand musculoskeletal complications among diabetic patients in Northwest Ethiopia.

\section{Methods}

\section{Study design, area and population}

An institution based cross-sectional study was conducted on 301 Ethiopian DM patients attending the Diabetes Clinic at the University of Gondar Teaching Referral Hospital, Northwest Ethiopia. The University of Gondar Teaching Referral Hospital, which is the only referral hospital in North Gondar Administrative zone, is located in Gondar town, $741 \mathrm{~km}$ away from Addis Ababa. The Diabetes Illness Care Follow up Clinic was organized two decades ago under the Outpatient Department in the University of Gondar Teaching Referral Hospital.

All DM patients registered and attending the Diabetic Clinic during the data collection, from March 27 to May 29,
2012, were included in the study. Out of this population, patients with congenital shoulder and hand musculoskeletal abnormalities, recent fracture or injuries, and surgery to the shoulder and the hand were excluded.

\section{Sample and sampling technique}

Sample size was determined by the formula for single population proportions, using the assumption of a $5 \%$ level of significance, marginal error of $5 \%$, and $10 \%$ nonresponse rate. On average, a total of 120 patients visited the Diabetic Clinic per week. Therefore, during the two months of data collection it was assumed 960 diabetic patients would be available. So the sample was taken from a relatively small population $(\mathrm{N}=960)$. The required sample size was obtained by the following calculation $(\mathrm{n}=$ sample size, $p=$ prevalence, $d=$ margin of error):

$n=z^{2} p(1-p) / d^{2}, n=(1.96) 2 x(0.5)(0.5) /(0.05)^{2}=384.16=384$ $\mathrm{n}=\mathrm{n} /(1+\mathrm{n} / \mathrm{N}), \mathrm{n}=384 /(1+384 / 960), \mathrm{n}=274.28=274+$ $10 \%$ non-response $=301$ Study subjects were selected using a systematic sampling procedure so that every $3^{\text {rd }}$ patient was selected.

\section{Data collection procedure}

Three qualified physiotherapy data collectors were used. All study subjects gave written consent, and were then interviewed for demographic information and history of MSK abnormalities related to frozen shoulder, limited joint mobility of the hand, carpal tunnel syndrome, trigger fingers and Dupuytren's contracture. Functional range of movement examination of the shoulder, palpation and observation of hand were performed. The prayer sign test and table top test were performed to assess limitations in joint mobility of the hand. The phalen sign and tinel sign tests were performed to assess the carpal tunnel syndrome. In this investigation, a shoulder and hand musculoskeletal complication was defined as the presence of a frozen shoulder and / or limited joint mobility and / or carpal tunnel syndrome and / or dupuytren's contracture and / or trigger finger. All assessments were performed by the data collectors without knowing which patients had a previous history of diabetic related shoulder and hand musculoskeletal complications [7].

\section{Data analysis}

Using the SPSS version 16 software, descriptive statistics were done for most variables in the study using statistical measurements: frequency tables, graphs, percentages, means and standard deviations. Bivariate logistic regression analysis was used to determine which variables had association with shoulder and hand complications. Variables found to have association with shoulder and hand complication were modeled with multivariate logistic regression to control for the effect of confounders. Finally, the variables which had significant association were identified on the basis of the odds ratio (OR), with $95 \% \mathrm{Cl}$ and less than 
Fasika et al. Journal of Diabetes Research \& Clinical Metabolism 2013,

Table 1. Demographic characteristics of diabetes subjects at University of Gondar Reaching Referral Hospital, May 2012, Gondar, $(n=301)$.

\begin{tabular}{|c|c|c|}
\hline Variable & $\mathbf{N}$ & $\%$ \\
\hline \multicolumn{3}{|l|}{ Sex } \\
\hline Female & 163 & 54.2 \\
\hline Male & 138 & 45.8 \\
\hline \multicolumn{3}{|l|}{ Residence } \\
\hline Urban & 202 & 66.9 \\
\hline Rural & 99 & 32.8 \\
\hline \multicolumn{3}{|l|}{ Occupation } \\
\hline Student & 24 & 8.0 \\
\hline Employee & 57 & 18.9 \\
\hline Trader & 31 & 10.3 \\
\hline Farmer & $\begin{array}{l}J 1 \\
62\end{array}$ & 20.6 \\
\hline House wife & $\begin{array}{l}02 \\
95\end{array}$ & 31.6 \\
\hline Retired & 18 & 6.0 \\
\hline Daily laborer & $\begin{array}{l}18 \\
9\end{array}$ & 3.0 \\
\hline Jobless & 5 & 1.7 \\
\hline \multicolumn{3}{|l|}{ Type of diabetes } \\
\hline Type 1 & 127 & 42.2 \\
\hline Type 2 & 174 & 57.8 \\
\hline \multicolumn{3}{|l|}{ Age (in years) } \\
\hline$\leq 20$ & 21 & 7 \\
\hline $21-30$ & 42 & 14 \\
\hline $31-40$ & 52 & 17.3 \\
\hline $41-50$ & 74 & 24.6 \\
\hline $51-60$ & 58 & 19.3 \\
\hline$\geq 61$ & 54 & 17.9 \\
\hline \multicolumn{3}{|l|}{ Duration of DM (in year) } \\
\hline$<7$ & 255 & 84.7 \\
\hline$\geq 7$ & 46 & 15.3 \\
\hline \multicolumn{3}{|l|}{ Type of current DM therapy } \\
\hline Lente insulin & 189 & 62.8 \\
\hline Glibenclamide & 55 & 18.3 \\
\hline Metformin & 4 & 1.3 \\
\hline Glibenclamide + metformin & 51 & 16.9 \\
\hline Regular + lente insulin & 2 & 0.7 \\
\hline
\end{tabular}

Table 2. Prevalence of shoulder and hand complication by subjects' sex, type of DM, age and duration of diabetics at University of Gondar Teaching Referral Hospital, May 2012, $(\mathrm{n}=301)$.

\begin{tabular}{lll}
\hline Variables & Yes, n (\%) & No, n (\%) \\
\hline Sex & $14(10.1)$ & $124(89.9)$ \\
Male & $36(20.1)$ & $127(77.9)$ \\
Female & & \\
\hline Type of DM & $13(10.2)$ & $114(89.8)$ \\
Type 1 & $37(21.3)$ & $137(78.7)$ \\
Type 2 & & \\
\hline Age in year & $2(9.5)$ & $19(90.5)$ \\
$\leq 20$ & $2(4.8)$ & $40(95.2)$ \\
$21-30$ & $8(15.4)$ & $44(84.6)$ \\
$31-40$ & $8(10.8)$ & $66(89.2)$ \\
$41-50$ & $14(24.1)$ & $44(75.9)$ \\
$51-60$ & $16(29.6)$ & $38(70.4)$ \\
$\geq 61$ & & \\
\hline Duration DM in years & $37(14.5)$ & $218(85.5)$ \\
$<7$ & $13(28.3)$ & $33(71.7)$ \\
$\geq 7$ &
\end{tabular}

0.05 p-values. Ethical approval was obtained from the University of Gondar Ethical Review Committee.

\section{Results}

Complete set of data was collected from 301 subjects with DM of which 163 (54.2\%) were female. The mean age
( \pm SD) of subjects was 45.9 ( \pm 15.9 ) years. The mean age $( \pm$ SD) of diabetes diagnosis was $39.9( \pm 16.2)$ years. Almost one third of the participants 127 (42\%) had type 1 DM. The mean duration of diabetic diagnosis ( \pm SD) was 6.0 ( \pm 5.9 ) years. Nearly all subjects 289 (96\%) were right hand dominant. More than half of the subjects 189 $(62.8 \%)$ used lente insulin as a medication which was followed by glibenclamide 55 (18.3\%) and combined glibenclamide and metformin 51 (16.9\%). Out of the total study subjects, $87(28.9 \%)$ had other known complications out of which hypertension was the highest 83 (27.6\%). The majority of subjects 95 (31.6\%) were house wives, 62 (20.6\%) were farmers, and self and government employed accounted for 57 (18.9\%) (Table 1).

The overall cumulative prevalence of shoulder and hand complications was $16.6 \%$. The highest prevalence was noted in female 36 (20.1\%). Shoulder and hand complication was 37 (21.3\%) prevalent in type 2 DM. The peak age specific prevalence was noted in age group of sixty one year and above 16 (29.6\%). A higher rate of shoulder and hand complication was observed in a reported duration of DM illness of 7 years and above 13 (28.3\%). (Table 2) The occurrence of shoulder and hand complication was two times $(O R=2.32)$ higher among DM subjects whose duration of DM is seven years and above and the difference is statistically significant $(p=0.02)$.

In this study, the prevalence of shoulder and hand complications was higher among urban dwellers $37(18.3 \%)$. Among the identified occupations for subjects, the proportion of shoulder and hand complications was higher in house wives group 24 (25.3\%).

Out of the total 301 subjects, carpal tunnel syndrome was the most common feature occurring in almost 88 (29.2\%) subjects, followed by limited joint mobility of the hands $61(20.3 \%)$ and the least identified type of shoulder and hand complication was dupuytren's contracture occurring in two subjects (Figure 1).

In a bivariate logistic regression analysis, shoulder and hand complications were associated significantly with sex, type of diabetes, age and duration of diabetes illness $(p<0.05)$. However, in multivariate logistic regression analysis, shoulder and hand complications were significantly associated only with $\operatorname{sex}(p=0.04)[A O R=2.068,95 \% \mathrm{Cl}$ : 1.035, 4.135] (Table 3).

\section{Discussion}

The incidence and the life expectancy of diabetic patients have both increased, resulting in increased prevalence and clinical importance of musculoskeletal alterations in diabetic subjects. In our study the prevalence of shoulder and hand complications among patients with diabetes was $16.6 \%$. This finding was comparable with results from Ibadan, Nigeria 19\% [15] and Lahti, Finland 14\% [8]. However, the finding of this study was lower than results from a study done in Gateshead, UK 23\% [13]. 
Table 3. Factors associated with shoulder and hand complication among diabetes patient at university of gondar teaching referral hospital by bivariate and multivariate logistic regression analysis may, 2012, Gondar Ethiopia, $(\mathrm{n}=301)$.

\begin{tabular}{|c|c|c|c|c|c|}
\hline \multirow[t]{2}{*}{ Variables } & \multicolumn{2}{|c|}{ Shoulder and hand complication } & \multirow[t]{2}{*}{ Crude OR (95\% CI) } & \multirow[t]{2}{*}{ Adjusted OR (95\% CI) } & \multirow[t]{2}{*}{$P$ - value } \\
\hline & Yes, $\mathbf{n}$ & No, $n$ & & & \\
\hline \multicolumn{6}{|l|}{ Sex } \\
\hline Female & 36 & 127 & $0.398(0.205,0.775)$ & $2.068(1.035,4.135)$ & 0.040 \\
\hline Male & 14 & 124 & 1 & 1 & - \\
\hline \multicolumn{6}{|c|}{ Type of diabetes } \\
\hline Type 1 & 13 & 114 & 1 & 1 & - \\
\hline Type 2 & 37 & 137 & $0.422(0.214,0.833)$ & $0.944(0.339,2.628)$ & 0.913 \\
\hline \multicolumn{6}{|c|}{ Age in years } \\
\hline$\leq 20$ & 2 & 19 & 1 & 1 & - \\
\hline $21-30$ & 2 & 40 & $0.250(0.052,1.201)$ & $0.292(0.060,1.425)$ & 0.128 \\
\hline $31-40$ & 8 & 44 & $0.119(0.260,0.551)$ & $0.151(0.320,0.718)$ & 0.017 \\
\hline $41-50$ & 8 & 66 & $0.432(0.166,1.120)$ & $0.472(0.180,1.238)$ & 0.127 \\
\hline $51-60$ & 14 & 44 & $0.288(0.113,0.735)$ & $0.286(0.111,0.737)$ & 0.009 \\
\hline $61 \geq$ & 16 & 38 & $0.756(0.327,1.748)$ & $0.721(0.309,1.684)$ & 0.450 \\
\hline \multicolumn{6}{|c|}{ Duration of diabetes in years } \\
\hline$\leq 6$ & 25 & 173 & 1 & 1 & - \\
\hline $7 \geq$ & 25 & 78 & $0.431(0.208,0.894)$ & $0.573(0.264,1.243)$ & 0.159 \\
\hline
\end{tabular}

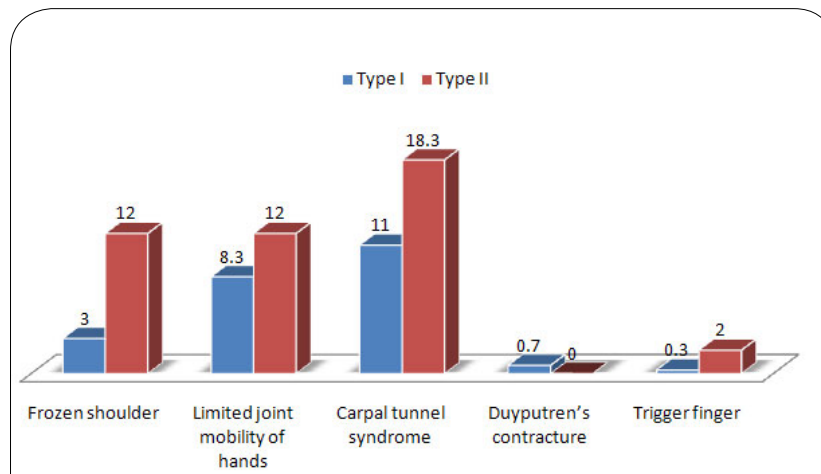

Figure 1. Prevalence of types of shoulder and hand complications by types of DM at University of Gondar Teaching Referral Hospital, May 2012, (n=301).

There are several explanations for differences in the prevalence of shoulder and hand complications in diabetic patients in Ethiopia. There were differences in the procedures used in various studies to measure prevalence. The criteria used to define the conditions varied and some studies measured only the shoulder whereas others looked at the hand or combined both shoulder and hand. Additional factors contributing to the variation in prevalence could be the type of subjects with DM (type 1 and type 2) selected for the study, either combined or separately, difference in sample size, study subjects' ethnic group [5], and other socio- economic aspects. Individual differences in the provision of health care as well as adherence to management to have good control of DM and to keep the musculoskeletal function supple by changing the life style, doing regular physical exercise, and strictly following prescribed diet management could also be reasons [5].

Similar to the study from Lahti, Finland [8], this study found higher rate of shoulder and hand complications in type 2 diabetes ( $21.3 \%$ vs. $10 \%)$, but this study showed no association between shoulder and hand complication and type 2 diabetes by multivariate analysis. Among the underlying reasons for the occurrence of a higher rate of shoulder and hand complications in type 2 is that type 2 DM is highly prevalent globally in $90 \%$ of the DM patients [5] and it may remain undiagnosed for many years. A further possible explanation is that type $2 \mathrm{DM}$ could be hyperglycemic for many years without being symptomatic, and consequently, the hyperglycaemia might cause pathological and functional changes for a long time before the diagnosis is made. Nevertheless, the exact pathophysiology of type $2 \mathrm{DM}$ leading to such complication is not yet fully understood [5].

In this study, shoulder and hand musculoskeletal complications were observed more frequently in female (22.1\%) subjects as compared with males (10.1\%). By multivariate logistic regression female diabetic subjects were more than two times more likely to develop shoulder and hand complications as compared to male subjects [AOR $=2.068,95 \% \mathrm{Cl}: 1.035,4.135]$. Other studies done in Aydin, Turkey [6], Ibadan, Nigeria [15] and Lahti Finland [8] also found that shoulder and hand complications occurred more frequently in females. A study done in Massachusetts General Hospital Diabetes Center, USA, verified that being female had a significant association with the presence of shoulder and hand musculoskeletal manifestations in patients with DM [3]. The likely explanations suggested were genetic, hormonal and the differential distribution in risk factors between male and female across populations [5]. In our study the gender disparity among respondents further varies according to occupational status. That is a house wife, in Ethiopian context, spends most of her time at home involving in house hold activities, which could expose her to low physical activity.

The computed proportion of shoulder and hand comp- 
lication differs, significantly with increasing age. In our finding the rate increased modestly with age between 31 to 40 years and between 51 to 60 years in the multivariate analysis model and, a study conducted in Turku, Finland [8] showed the prevalence of shoulder complication increased with age, with peak prevalence is in the oldest age-group. Although the exact scientific evidence is lacking, uncontrolled hyperglycemia of DM develops gradually with age [5]. DM affects connective tissues in many ways and causes different alterations in periarticular and skeletal systems of the shoulder and hand also it is evident that the development of shoulder and hand musculoskeletal disorder is dependent on age and the duration DM [5].

According to several studies, duration of DM is a predictor of shoulder and hand musculoskeletal. A study conducted in USA [3] showed only longer duration of DM had association with the presence of shoulder and hand complication. Similarly a study done in Kerala, India identified a higher frequency (52.9\%) of DM of more than 5 years duration [16]. In contrast to previous studies that found duration of diabetes to be significant, this study showed no significant association between the occurrence of shoulder and hand complications and duration of DM in a multivariate logistic regression model. In this study most of the subjects $84.7 \%$ reported duration of DM illness less than 7 years. In this study most of the subjects reported short duration of DM and short duration of DM may be explained by the fact that known duration DM is probably an inaccurate marker of the true duration of the diseases in many patients with DM [8].

\section{Conclusion}

In agreement with other studies, this study has found high prevalence of shoulder and hand musculoskeletal complications in Northwest Ethiopian DM patients. Shoulder and hand musculoskeletal complications are significantly high in female and in older diabetes mellitus patients in Ethiopia. Therefore examination of the shoulder and the hand should be carefully addressed by health care providers.

\section{Competing interests}

The authors declare that they have no competing interests.

\section{Acknowledgement}

We would like to forward our deepest gratitude

to all subjects included in this study. Without

their cooperation this study would have not been

possible. We would like to add our special thanks to the University of Gondar for funding the study.

Publication history

Received: 19-Nov-2012 Revised: 28-Dec-2012

Re-Revised: 18-Jan-2013 Accepted: 03-Feb-2013

Published: 12-Feb-2013

\section{References}

1. Whiting DR, Guariguata L, Weil C and Shaw J: IDF diabetes atlas: global estimates of the prevalence of diabetes for 2011 and 2030. Diabetes Res Clin Pract 2011, 94:311-21. I Article I PubMed
2. Arkkila PE, Kantola IM, Viikari JS and Ronnemaa T: Shoulder capsulitis in type I and II diabetic patients: association with diabetic complications and related diseases. Ann Rheum Dis 1996, 55:90714. I Article | PubMed Abstract | PubMed Full Text

3. Cagliero E, Apruzzese W, Perlmutter GS and Nathan DM: Musculoskeletal disorders of the hand and shoulder in patients with diabetes mellitus. Am J Med 2002, 112:487-90. | Pdf | PubMed

4. Kim RP, Steven VE, and Dennis DK: Musculoskeletal Complications of Diabetes Mellitus. Clinical Diabetes 2001, 19:132 -135. I Article

5. Arkkila PE and Gautier JF: Musculoskeletal disorders in diabetes mellitus: an update. Best Pract Res Clin Rheumatol 2003, 17:945-70. | Article | PubMed

6. Aydeniz A, Gursoy S and Guney E: Which musculoskeletal complications are most frequently seen in type $\mathbf{2}$ diabetes mellitus? J Int Med Res 2008, 36:505-11. I Article I PubMed

7. Ardic F, Soyupek F, Kahraman Y and Yorgancioglu R: The musculoskeletal complications seen in type II diabetics: predominance of hand involvement. Clin Rheumatol 2003, 22:22933. | Article | PubMed

8. Arkkila PE, Kantola IM, Viikari JS and Ronnemaa T: Shoulder capsulitis in type I and II diabetic patients: association with diabetic complications and related diseases. Ann Rheum Dis 1996, 55:90714. | Article | PubMed Abstract | PubMed Full Text

9. Lequesne M, Dang N, Bensasson M and Mery C: Increased association of diabetes mellitus with capsulitis of the shoulder and shoulder-hand syndrome. Scand J Rheumatol 1977, 6:53-6. I Article I PubMed

10. Balci N, Balci MK and Tuzuner S: Shoulder adhesive capsulitis and shoulder range of motion in type II diabetes mellitus: association with diabetic complications. J Diabetes Complications 1999, 13:13540. I Article I PubMed

11. Tighe CB and Oakley WS, Jr.: The prevalence of a diabetic condition and adhesive capsulitis of the shoulder. South Med J 2008, 101:5915. | Article | PubMed

12. Smith LL, Burnet SP and McNeil JD: Musculoskeletal manifestations of diabetes mellitus. Br J Sports Med 2003, 37:30-5. | Article | PubMed Abstract | PubMed Full Text

13. Ramchurn N, Mashamba C, Leitch E, Arutchelvam V, Narayanan K, Weaver J, Hamilton J, Heycock C, Saravanan V and Kelly C: Upper limb musculoskeletal abnormalities and poor metabolic control in diabetes. Eur J Intern Med 2009, 20:718-21. I Article I PubMed

14. Fitzgibbons. PG, Weiss. AP.C: Hand Manifestation of Diabetes Mellitus. Journal of Hand Surgery 2008, 33: 771-775. I Pdf

15. Akanji AO, Bella AF and Osotimehin BO: Cheiroarthropathy and long term diabetic complications in Nigerians. Ann Rheum Dis 1990, 49:28-30. | Article | PubMed Abstract | PubMed Full Text

16. Mathew AJ, Nair JB and Pillai SS: Rheumatic-musculoskeletal manifestations in type 2 diabetes mellitus patients in south India. Int J Rheum Dis 2011, 14:55-60. I Article I PubMed

\section{Citation:}

Fasika S, Abebe S M and Kebede A G: The prevalence of shoulder and hand complications and associated factors among diabetic patients at University of Gondar Teaching Referral Hospital in Northwest Ethiopia. Journal of Diabetes Research and Clinical Metabolism 2013, 2:8.

http://dx.doi.org/10.7243/2050-0866-2-8 